\title{
Retraction Note: Detection of soil pollution in hilly area based on Bayesian network and optimization of child allowance system
}

Wei $\mathrm{Li}^{1,2} \cdot \mathrm{Qi}^{\mathrm{Ding}}{ }^{1}$

Published online: 18 November 2021

(c) Saudi Society for Geosciences 2021

Rectraction Note: Arabian Journal of Geosciences (2021) 14: 1715 https://doi.org/10.1007/s12517-021-08030-1

The Editor-in-Chief and the Publisher have retracted this article because the content of this article is nonsensical. The peer review process was not carried out in accordance with the Publisher's peer review policy. The authors have not responded to correspondence regarding this retraction.

The original article can be found online at https://doi.org/10.1007/ s12517-021-08030-1.

Wei Li

lw_zuel@163.com

1 School of Philosophy, Zhongnan University of Economics and Law, Wuhan, China

2 School of Sociology, Huazhong University of Science and Technology, Wuhan, China 